\title{
Study on the Construction of Virtual Cluster Hotel Supply Chain Model Bi Lifang ${ }^{1}$,Wu Bing ${ }^{2}$
}

\author{
${ }^{1}$ Kunming College, Kunming, Yunnan Province 650214, P.R. China \\ ${ }^{2}$ Shaanxi Normal University, Xi’an, Shaanxi Province 710062, P.R. China
}

Xuexi123@163.com

Keywords: Single regression, Least square, Maximum likelihood estimation, Supply chain, Cohesion, Driving force.

\begin{abstract}
Hotel external expansion is more inclined to network virtual operation. The geographically centralized competitive advantage industry cluster has become weaker in the globalization activities space and the network economic environment. In order to study the hotel cluster supply chain under the new cluster competition mode, according to the principle of system dynamics, this paper establishes the cohesion and driving force mathematical model of the industry chain cluster. Through single linear regression and least-squares algorithm, this paper obtained the maximum likelihood estimators of supply chain, and evaluates the hotel competitive balance degree relationship under the cluster mode. Finally through the MATLAB numerical simulation, the competitive equilibrium curve before and after the cluster industrial chain optimization is obtained, which provides the theory reference for the research on the hotel cluster development models.
\end{abstract}

\section{Introduction}

With the rapid development of modern network economy and network communication technology, the advantage of original geography centralized high tech industry cluster is gradually weakened, and the virtualization network operation mode provides a new way for high technology industrial cluster operating and developing in cross regional cooperation, so the high technology virtual industrial cluster emerge as the times require, especially the service industries of hotel and tourism [1,2]. Virtual network and cluster development model provide great cohesion and driving force. Assuming the cluster mode is through two distributions, establishing chain structure, and its development model is as shown in Figure 1.

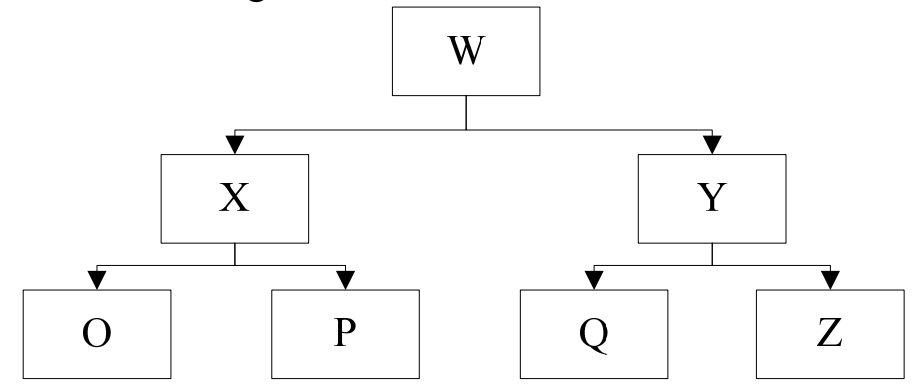

Fig. 1 The figure of hotel cluster development mode

As shown in Figure 1, in order to make the hotel cluster model $W-X-O-Q$ association, there are two ways: one is the $O$ back to $X$ and then find the association with $Q$ from $Y$ directly, and it also can find the association with $Q$ from historical record in $Y$ [3]; the other is $Q$ back to $Y$, and find the association with $O$ directly from $X$.

\section{The Virtual Cluster Hotel Supply Chain Model Design}

The hotel cluster industry chain has a mesh topology, in order to study the operation model of industrial clusters; this paper establishes the virtual model of hotel industry chain, and carries on the 
research on each node in the cluster network [4-6]. The industrial chain is mainly affected by five respects.

$$
Q=P_{f}+Z_{f}+Z_{j}-S_{l}-S_{d} \text {. }
$$

$Q$ is the competition balance of industrial cluster; $P_{f}$ is cluster total assets; $Z_{f}$ is input gain; $Z_{j}$ is profit gain; $S_{d}$ is the property loss when the cluster sample number is $d$. Its expression can be written as:

$$
S_{d}=S_{d}\left(d_{0}\right)+10 n \log _{10}\left(\frac{d}{d_{0}}\right)+X_{\sigma} .
$$

$d_{0}$ is the reference sample number; $S_{d}\left(d_{0}\right)$ is investment losses in the reference sample; $X_{\sigma}$ is difference supplementary terms; If $S_{d}=y, 10 \log _{10}(d)=x$, through a linear regression change, the formula (2) can be written as:

$$
y=\lambda+n x+X_{\sigma} .
$$

(3)

Each industry cluster can use an independent sequence $\left(x_{1}, y_{1}\right),\left(x_{2}, y_{2}\right), \cdots,\left(x_{n}, y_{n}\right)$ to represent.

$$
y=\lambda+n x_{i}+X_{\sigma i} .
$$

(4)

Then it uses the least squares method to do estimation on virtual industry assets.

$$
\widehat{n}=\frac{\sum_{i=1}^{m}\left(x_{i}-\bar{x}\right)\left(y_{i}-\bar{y}\right)}{\sum_{i=1}^{m}\left(x_{i}-\bar{x}\right)^{2}} .
$$

$$
\bar{x}=\frac{1}{m} \sum_{i=1}^{m} x_{i}, \quad \bar{y}=\frac{1}{m} \sum_{i=1}^{m} y_{i} .
$$

The $\sigma$ maximum likelihood estimation value in $X_{\sigma}$ can be written as shown in formula (7).

$$
\widehat{\sigma}=\sqrt{\frac{1}{m} \sum_{i=1}^{m} x_{\sigma_{i}}{ }^{2}} .
$$

(7)

So the ultimately competition balance degree of industrial cluster can be written as:

$$
f\left(S_{d}\right)=\frac{1}{\hat{\sigma} \sqrt{2 \pi}} e^{\frac{-\left[S_{d}-\left(P_{f}+Z_{f}+Z_{j}-S_{l}-S_{d}\right)\right]}{2 \sigma^{2}}} .
$$

In order to realize balance algorithm of industrial cluster competition cohesion force and driving force, this paper adopts MATLAB software to design the algorithm, and the program is as follows:

title(' Virtual cluster database ');

subplot(212);

$\mathrm{yf}=\mathrm{abs}(\mathrm{fft}(\mathrm{y}))$;

$\mathrm{yf}=\mathrm{yf}(1: \lg / 2)$; 


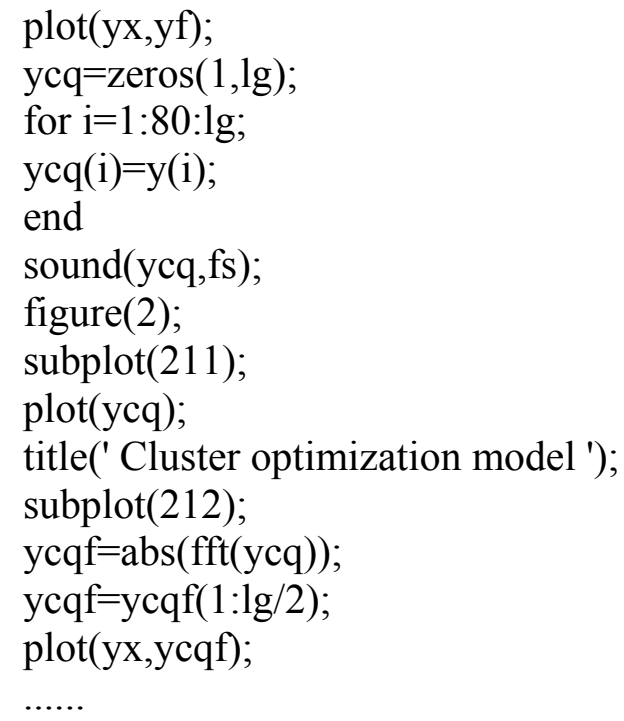

\section{Research on Hotel Supply Chain Virtual Cluster Simulation}

In order to effectively verify the effectiveness and reliability of industrial cluster virtual competitiveness model designed in section second, this paper designs cluster database of virtual hotel supply chain, and uses MATLAB to analyze the data [7, 8]. The database schema used is as follows:

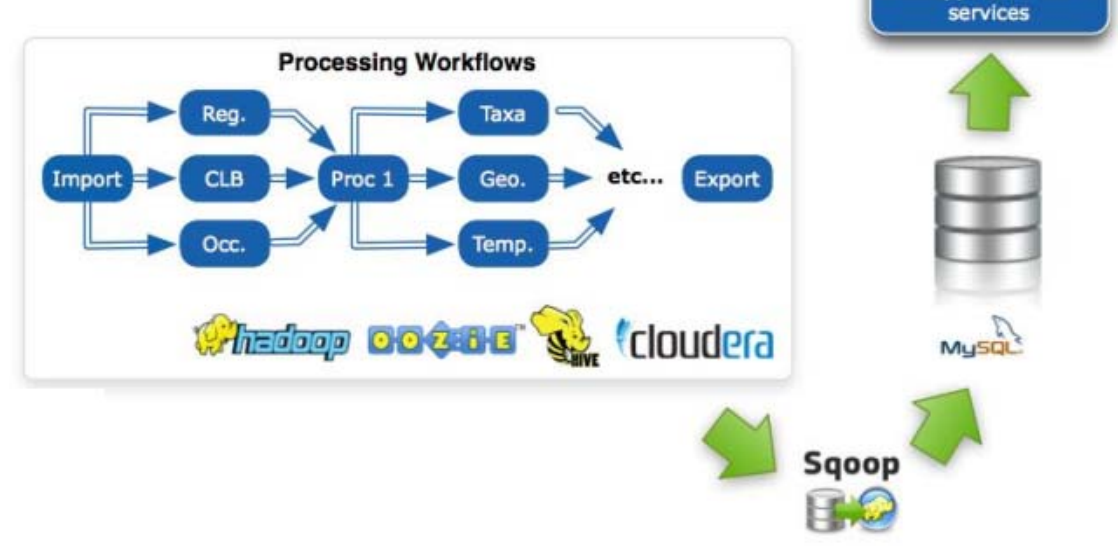

Fig. 2 Virtual hotel industry supply chain MySQL database

Figure 2 shows the virtual hotel industry supply chain MySQL database. In the bottom of the model, they are various types of data of the hotel investment, profit and the comprehensive competition [9]. The supply chain will treat the corresponding data. The top layer is Web server. 


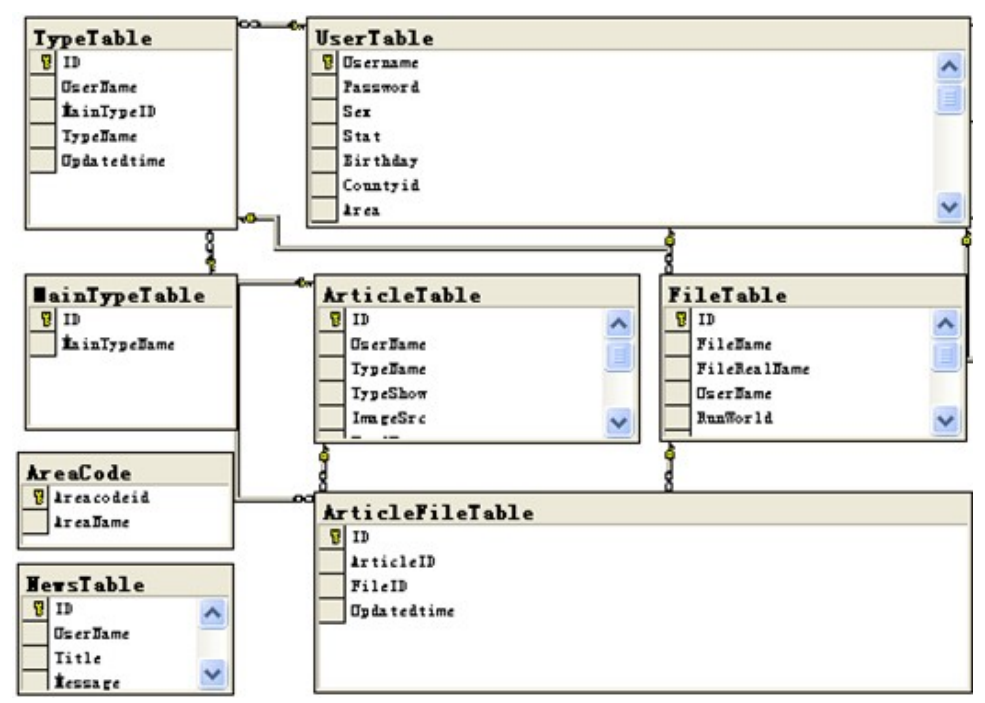

Fig. 3 Virtual supply chain data model

Figure 3 shows the top-level of virtual supply chain data model. The layer is a Web server, besides the output of calculation result; it can also carry out real-time changes on the data [10]. Through the Web server it will feedback the data and obtains the reasonable database.

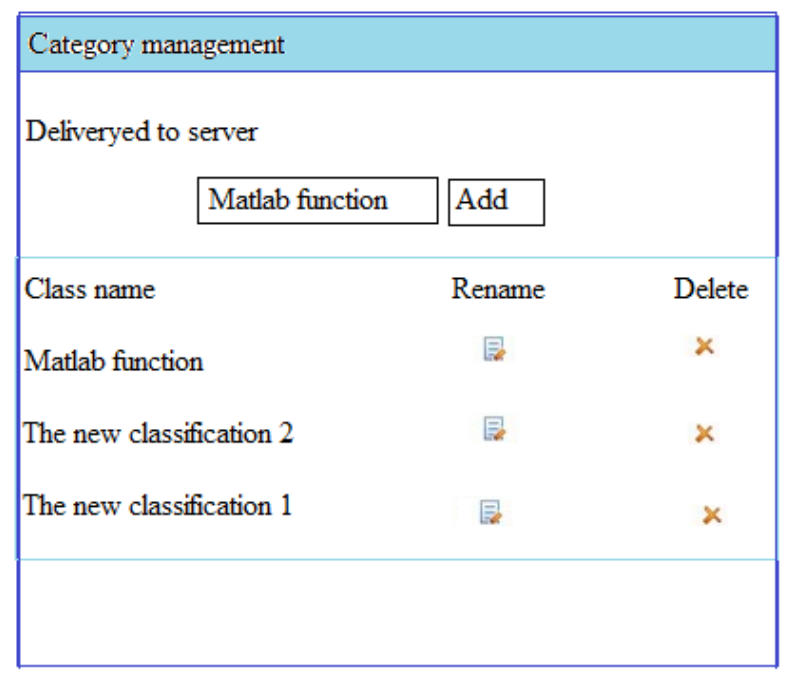

Fig. 4 MATLAB classification calculation

Figure 4 shows the MATLAB classification calculation window [11]. In the virtual hotel supply chain mode, the main influence of cohesive force and driving force in the hotel industry benefit is the competition under various modes, and electronic business has an important position in the competition, considering the influence of electric data, the calculated distribution is as shown in Figure 5.

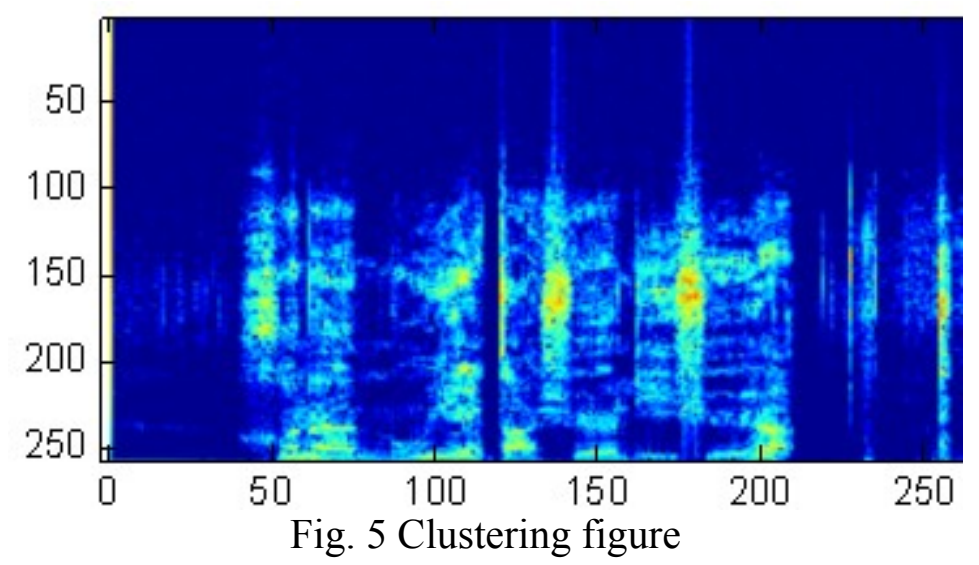


Figure 5 shows the clustering pattern of clusters. According to system dynamics theory, under the influence of clusters cohesion, each hotel has different gains in cluster [12]. The red part is some hotels have been in the red alert in the competition, and it needs to carry on the adjustment.

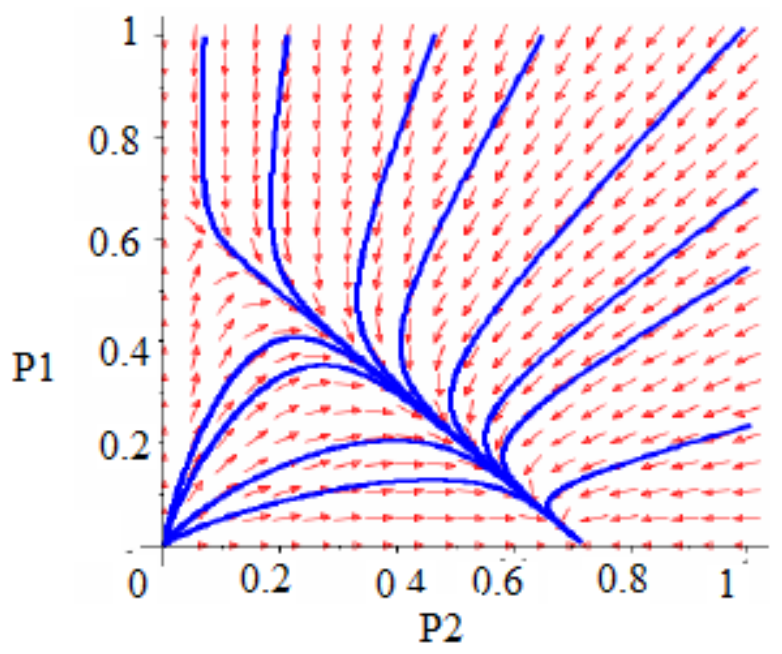

Fig. 6 Cluster industrial chain model

As shown in Figure 6, through the cooperative and competitive co-evolution analysis, this paper obtained the clustering driving effect chart of hotel cluster industry chain $[13,14]$. From the chart it can be seen, when the system evolution time is $t \rightarrow \infty$, the system finally trend to be divergence, which is not conducive to the development of hotel integrated supply chain.

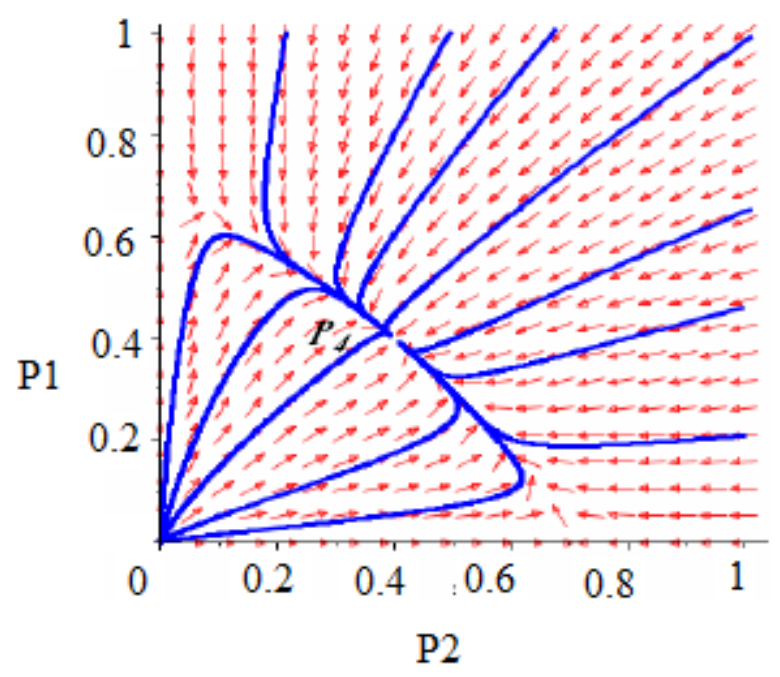

Fig. 7 Optimization model of cluster industry chain

It can be seen from Figure 7, the evolution state is the effective equilibrium of cluster supply chain cooperation [16]. When the system evolution time is $\rightarrow \infty$, the system tends to be the equilibrium point $P_{4}$, which promotes the effective cooperation and moderate competition relations of industrial cluster supply chain value.

\section{Summary}

Based on the single linear regression and least squares algorithm, combined with the maximum likelihood estimation of hotel supply chain, this paper designs the hotel virtual cluster competitiveness model, and studies the cluster industry chain, finally gets the virtual industry cluster optimization model moderate competition relations under the modern network economy environment. This paper uses MATLAB to do numerical simulation on the hotel industry cluster supply chain balance relationship, and gets competitive equilibrium curve of before and after the optimization of cluster industrial chain model. The optimized model has equilibrium point of the system, so as to promote effective cooperation and moderate competition of hotel industry cluster. 


\section{Acknowledgements}

Fund project: 2013 China National Natural Science Fund Project, "an equitable distribution of value-added benefits of rural tourism in Yunnan Land Mechanism" (G30).

\section{References}

[1] L.L. Xu, C.L. Liu, J. Liu. Game Analysis of chain cluster supply chain based on knowledge spillover effect and crowding. Logistics technology, 2013, 4(3): 12-15.

[2] C.Y. Gao. Study on economic benefit of joint managed inventory. Economics and management, 2013, 5(2): 62-65.

[3] Z.M. Tang. Supply chain management mode of VMI and TPL integration. Technology economy and management research, 2013, 4(1): 24-28.

[4] H.B. Zhu, X.Y. Li. The across chain inventory cooperation model of cluster supply chain. Journal of systems management in, 2013, 5(1): 45-48.

[5] X.J. Zhou, J.Z. Li, A.H. Liu. Cluster supply chain optimization model based on value analysis. Reform and strategy, 2012, 4(11): 71-75.

[6] H.Y. Huang, Z.X. Liu. The cluster supply chain inventory coordination control with the third party logistics. Industrial engineering and management, 2012, 6(5): 115-119.

[7] X.B. Liu, F.J. Cui, J.D. Zhang, Y.J. Wang. Study on application of resource consumption accounting in the iron and steel enterprise information. Chinese information management, 2013, 2(20): $25-29$.

[8] M.L. Zhou, H.X. Xue, K.J. Lu, Q.M. Zhang. Cluster supply chain collaborative management review for small and medium enterprises. Chinese manufacturing information, 2012 4(17): 36-39.

[9] M.L. Zhou, H.X. Xue. Planning and design of environment management accounting information systems. Chinese manufacturing industry information, 2012, 3(15): 32-36.

[10] M.L. Zhou, H.X. Xue, H.Z. Zhang. Effect analysis of the agricultural industry cluster - based on the economic data of Jiangsu. Technology economic, 2013, 4(7): 89-91.

[11] J.Q. Cao, J.B. Li, W. Gong. Enterprise procurement management system. China informatization of manufacturing industry, 2012, 4(1): 72-75.

[12] S.W. Zheng, F. Fang. Research on digital platform model construction of the travel agency industry in China. Commercial research, 2013, 4(2): 32-35..

[13] X.Y. Lv, H. Xu, Y.M. Yang. Study on tourists power from supply chain perspective. Tourism tribune, 2013, 4(11): 25-29.

[14] P. Yu, Y.L. Lu. China's tourism electronic business model innovation research and platform design. Computer and modernization, 2013, 4(7): 53-56.

[15] C.F. Huang, H. Sun, L.Z. He. Chinese tourism industry chain recognition. Tourism journal, 2012, 4(1): 65-69.

[16] X.Y. Lv, H. Xu, M. Yin. Tourism supply chain enterprises channel relationship game analysis based on channel power theoy. Journal of travel, 2012, 2(12): 36-39. 